\title{
Eudragit S-100 Encapsulated Chitosan Coated Liposomes Containing Prednisolone for Colon Targeting: In vitro, Ex vivo and In vivo Evaluation
}

\author{
Mascarenhas Shanon Ben*, Koland Marina, Ghetia Sawan Mukund \\ Department of Pharmaceutics, NGSM Institute of Pharmaceutical Sciences, NITTE Deemed to be University, Mangalore, Karnataka, INDIA.
}

\begin{abstract}
Objective: The present study was carried out to design an efficient formulation to target the drug loaded liposomes exclusively to the inflamed colonic region by protecting the payload from releasing in the upper gastro intestinal tract (GIT) by using two polymers. Methods: Liposomes were prepared by lipid film hydration method followed by chitosan coating and finally encapsulation with eudragit S-100. The coated as well as uncoated liposomes were characterized for entrapment efficiency, size and surface charge. In vitro drug release study was carried out using three step $\mathrm{pH}$ gradient method. Acetic acid was used to induce colitis. Ex vivo tissue drug entrapment study was done using excised tissues of male albino rats. In vivo efficiency study was done by comparatively studying the histopathology and myeloperoxidase (MPO) activity. Results: Formulations showed entrapment efficiency $(93-91 \%)$ and size $(99-290 \mathrm{~nm})$. Formulation showed $\mathrm{T}_{\text {lag }}$ of $6 \mathrm{hrs}$ and by the end of $16^{\text {th }} \mathrm{h}, 82 \%$ drug release was achieved. Ex vivo studies revealed higher tissue-drug entrapment $(22.58 \pm 2.52 \%)$ in inflamed colon when compared to healthy colon $(22.58 \pm 2.52 \%)$. Histopathological studies showed marked reduction in inflammation in case of ECLs (eudragit encapsulated chitosan coated liposomes) treated groups than standard drug
\end{abstract}

treated rats. The reduction in healing was further confirmed by the MPO assay which showed significant reduction in MPO $(900.25 \pm 1.31 \mathrm{ng} / \mathrm{ml}) \mathrm{lev}-$ els of ECL treated groups than standard drug treated $(1990.32 \pm 2.11 \mathrm{ng} /$ $\mathrm{ml}$ ) and IBD group $(2125.54 \pm 1.56 \mathrm{ng} / \mathrm{ml})$. Conclusion: The ECLs showed site specific release of liposomes and increased accumulation of liposome entrapped drug in the inflamed colon.

Key words: Acetic acid induced rat colitis, Colon targeting, Ex vivo tissue entrapment, Histopathological studies, IBD, MPO activity.

\section{Correspondence}

Mr. Shanon Ben Mascarenhas, Department of Pharmaceutics, NGSM Institute of Pharmaceutical Sciences, NITTE Deemed to be University, Mangalore, Karnataka, , INDIA.

Phone: +917975872751

Email: shanonm47@gmail.com

DOI: 10.5530/jyp.2019.11.2

\section{INTRODUCTION}

Targeting drug to the colon is desired in case of several pathological conditions. The ailments may range in severity from mild constipation and diarrhoea to more serious inflammatory bowel disease (IBD) like ulcerative colitis (UC) and Crohn's disease (CD) which may further progress to cancer. Several orally administered drugs that can act locally are either absorbed or deactivated in the upper GIT. The drugs that are absorbed may further produce unwanted systemic effects. Hence oral dosage forms that deliver high concentrations of the drug to the colon instead of upper GIT are desirable to treat colonic ailments. ${ }^{1,2}$

Prednisolone is a corticosteroid used in IBD to control symptoms and inducing remission in both UC and CD. Apart from the pharmacological actions, the drug has multitude of adverse systemic reactions following upper GI absorption. ${ }^{3}$ Hence prednisolone was selected as a drug candidate for colon targeting. The present study is aimed at formulating prednisolone loaded liposomes coated with a biodegradable polysaccharide chitosan and then encapsulated within a $\mathrm{pH}$ sensitive eudragit S-100 shell. In vitro drug release study will be followed by ex vivo tissue-drug entrapment determination and in vivo efficiency study of the formulation. In vivo study that is conducted to determine the efficiency of the colon targeted formulation and compare it with standard prednisolone given orally is done using acetic acid induced rat colitis model. The efficiency is evaluated by microscopic examination of stained colonic tissue sections as well as determination of inflammatory marker enzyme MPO.

\section{MATERIALS AND METHODS}

\section{Materials}

Prednisolone B.P sample was gifted by Tianjin Tianyao Pharmaceuticals Ltd, China. Soy Phosphatidyl Choline (SPC) was gifted by LIPOID, Germany. Cholesterol was purchased from Lobachemie, India. Chitosan (Himedia labs) and Eudragit S-100 (Lobachemie) were used as polymers for coating the liposomes. Sodium taurocholate was procured from lobachemie and $\beta$-glucosidase and horse radish peroxidase from Himedia labs. All other reagents and solvents used were of analytical grade.

\section{Approval from animal ethical committee}

All procedures of the animal experimentation were approved by Institutional ethical committee of NGSM Institute of Pharmaceutical Sciences, NITTE deemed to be university, Karnataka, India under approval No. NGSMIPS/IAEC/MARCH-2018/87.

\section{Animals}

Male albino wistar rats of around 3 months old and weighing between 250-300 g were selected. The animals were procured from the animal house of NGSM Institute of Pharmaceutical Sciences, Mangalore, Karnataka, India. The animals were housed in cages kept in a room maintained at $25 \pm 2^{\circ} \mathrm{C}$ with alternating $12 \mathrm{~h}$ light and dark conditions. Rats were given $\mathrm{RO}$ water and commercial rat feed. Not more than 3 rats were housed in one cage. 


\section{METHODS}

\section{Preparation of liposomes}

Lipid film hydration method was used to prepare liposomes. ${ }^{4}$ Prednisolone $(10 \mathrm{mg})$, SPC $(60 \mathrm{mg})$ and cholesterol $(30 \mathrm{mg})$ were dissolved in $10 \mathrm{ml}$ chloroform. The clear solution obtained was dried on the inner walls of an $800 \mathrm{ml}$ round bottom evaporating flask of a rotary evaporator at $50-55^{\circ} \mathrm{C}$ under vacuum. The lipid film was further dried by keeping the flask overnight in vacuum dessicator. ${ }^{5}$ The dried film was then hydrated with $10 \mathrm{ml}$ phosphate buffer $\mathrm{pH} 7.4$ at $60-70^{\circ} \mathrm{C}$ and swirled for $15 \mathrm{~min}$ to form dispersion. The vesicles were downsized using a probe sonicator (Vibracell-sonics) for $5 \mathrm{~min}$ at 35\% amplitude with cycles of $50 \mathrm{sec}$ ON and $10 \mathrm{sec}$ OFF. The size reduced vesicles were then stored at $4^{\circ} \mathrm{C} .{ }^{6}$

\section{Coating liposomes with Chitosan}

A $2 \% \mathrm{w} / \mathrm{v}$ chitosan solution was prepared in $0.5 \% \mathrm{v} / \mathrm{v}$ acetic acid by stirring for $24 \mathrm{~h}$. Liposomal dispersion was slowly added to equal volume of chitosan solution drop wise under continuous magnetic stirring which was continued for $15 \mathrm{~min}$ after which the coating was allowed to stabilize by overnight refrigeration. Then the coated liposomes were purified by several cycles of centrifugation and washing with $0.5 \% \mathrm{v} / \mathrm{v}$ acetic acid to remove excess chitosan. Finally the coated liposomes were dispersed in deionized water and stored at $4^{\circ} \mathrm{C}$ until encapsulation process. ${ }^{7}$

\section{Encapsulation of Chitosan coated liposomes within eudragit S-100 shell}

A pH driven nano-precipitation method was done entirely in aqueous media thus achieving encapsulation without using any organic solvents that leave traces. ${ }^{8}$ In, brief eudragit S-100 was solubilized in phosphate buffer $\mathrm{pH}$ 8. This alkaline polymer solution was mixed with equal volume of Chitosan coated liposome dispersion (solution A). This solution A was then added drop wise using a syringe into a beaker containing $0.25 \% \mathrm{v} / \mathrm{v}$ acetic acid solution (solution B) under magnetic stirring in a ratio of 1:9 of solution $A$ and $B$ respectively. The sudden drop in $\mathrm{pH}$ induces precipitation of eudragit around coated vesicles. Stirring was continued for $15 \mathrm{~min}$ followed by cycles of centrifugation at 10,000 rpm and washing with deionized water. The final pellet was redispersed in $10 \mathrm{ml}$ deionized water and stored at $4^{\circ} \mathrm{C}$ until further analysis.

\section{Particle size, zeta potential (ZP) and percentage entrapment efficiency (\%EE) determination}

Plain liposomes, Chitosan Coated Liposomes (CCLs) and Eudragit Encapsulated Chitosan Coated Liposomes (ECLs) were analyzed for size and ZP using Malvern-Nano S particle size analyzer which uses principle of dynamic light scattering and electrophoretic mobility of particles. ${ }^{9,10}$

To determine $\% \mathrm{EE}, 1 \mathrm{ml}$ aliquots of formulations were centrifuged at $15,000 \mathrm{rpm}$ for $15 \mathrm{~min}$ at $4^{\circ} \mathrm{C}$. The pellets were sonicated with $10 \mathrm{ml}$ acetonitrile for $15 \mathrm{~min}$ to release the entrapped drug and then ultra centrifuged to separate the polymer and lipid residues from the drug in the supernatant. The supernatant was analyzed using HPLC (Shimadzu, Japan) and \%EE was calculated using the equation,

Where,

$$
\% \mathrm{EE}=\left[\mathrm{C} / \mathrm{C}_{\mathrm{d}}\right] \times 100
$$

$\mathrm{C}=$ Concentration of drug in supernatant

$\mathrm{C}_{\mathrm{d}}=$ Total drug in aliquot

\section{In vitro drug release study}

Drug release studies were performed by three step release method in three different simulated media. ${ }^{11}$ Aliquots equivalent to $5 \mathrm{mg}$ of prednisolone were placed in dialysis bag (Himedia) fastened to the paddle shaft of the dissolution apparatus and descended into $400 \mathrm{ml}$ dissolution media maintained at $37 \pm 0.5^{\circ} \mathrm{C}$. The paddle speed was set to $50 \mathrm{rpm}$. Drug release study was performed using HCL buffer pH $1.2(0.2 \mathrm{M}$
$\mathrm{HCl}$ and $0.2 \mathrm{M} \mathrm{KCl}$ mixed buffer (gastric condition) for $2 \mathrm{~h}$, phosphate buffer pH 7.4 containing model bile salt sodium taurocholate (small intestinal condition) for $3 \mathrm{~h}$ and phosphate buffer $\mathrm{pH} 6.8$ (colonic condition) containing enzyme $\beta$-glucosidase for chitinolytic action for up to $11 \mathrm{~h}$. Samples were withdrawn from the media at $30 \mathrm{~min}$ intervals for gastric conditions, at $1 \mathrm{~h}$ intervals for intestinal conditions and $2 \mathrm{~h}$ intervals for colonic conditions. Equal volume of fresh media was replenished after each sample withdrawal to maintain the sink conditions. The aliquots were filtered and analyzed for prednisolone concentration using HPLC.

\section{Induction of colitis in rats and treatment}

For experimentation, 30 rats were randomly divided into 5 groups: Healthy (no IBD, no treatment); Disease control (IBD, no treatment); Formulation treated (IBD, ECLs = equivalent to $5 \mathrm{mg} / \mathrm{kg} /$ day); Standard drug treated $(\mathrm{IBD}$, drug solution $=5 \mathrm{mg} / \mathrm{kg} /$ day); Placebo (IBD, ECLs without drug). After an overnight fasting, the rats were lightly anaesthetized with ether and IBD was induced by rectal administration of $1 \mathrm{ml}$ of $4 \%$ acetic acid using an infant urinary catheter at $8 \mathrm{~cm}$ proximal to the anus for $30 \mathrm{~s}$. To flush the colon, $1 \mathrm{ml}$ of phosphate buffered saline (PBS) was similarly administered. The formulation, placebo and prednisolone was suspended in $1 \mathrm{ml}$ saline and administered to the respective groups using gavages once daily from the fifth day after colitis induction and continued for 3 consecutive days. ${ }^{12}$

\section{Sacrification and subsequent excision of tissues}

Three days after drug treatment, the rats were sacrificed by high dose of ether inhalation. After sacrificing, a midline incision was made and stomach, a segment of small intestine and large intestine (about $3.5 \mathrm{~cm}$ ) were quickly excised, washed with saline. The tissues were then divided as per the requirement of ex vivo study and histopathological analysis.

\section{Ex vivo tissue-drug entrapment study}

After sacrificing, stomach, small intestine and large intestine of healthy and disease control groups were washed gently with Krebs Ringer Bicarbonate (KRB) solution (sodium chloride $118 \mathrm{mmol} / \mathrm{L}$, sodium bicarbonate $25 \mathrm{mmol} / \mathrm{L}$, potassium dihydrogenphosphate $1.19 \mathrm{mmol} / \mathrm{L}$, calcium chloride $1.03 \mathrm{mmol} / \mathrm{L}$, magnesium sulfate $1.2 \mathrm{mmol} / \mathrm{L}$, glucose $5 \mathrm{mmol} / \mathrm{L}$ albumin $1 \% ; \mathrm{pH}=7.4$ ) and everted using a glass rod inserted through the lumen. One end of the colon was tied to a needle and the opposite end was tied securely. ${ }^{13}$ Continuous drug release method was employed by changing the $\mathrm{pH}$ of the mucosal media. Initially, the everted stomach was cannulated with the help of a needle and other end was ligated. The sac was filled with $2 \mathrm{ml}$ of KRB solution was poured through the hypodermic needle. ${ }^{14}$ The sac was lowered in to $100 \mathrm{ml}$ simulated gastric media $\mathrm{pH} 1.2$ with aeration at $37^{\circ} \mathrm{C}$. In absorption studies, air was bubbled into the intestinal to obtain intestinal peristaltic movement. At the end of $2 \mathrm{~h}$, the stomach sac was removed and the contents were transferred to everted small intestine sac treated in similar manner as the stomach. $33.3 \mathrm{ml}$ of tribasic sodium phosphate was added to all the outer media and the $\mathrm{pH}$ was adjusted to $6.8(3 \mathrm{~h})$ along with sodium taurocholate. The sac was lowered into this media and process was continued. At the end of $5^{\text {th }} \mathrm{h}$, the small intestine content was transferred to everted colon sac. One end was probed with a needle and other. $2 \mathrm{M} \mathrm{NaOH}$ was added to the outer media and $\mathrm{pH}$ was adjusted to $7.2 .{ }^{15} \beta$-glucosidase was also added to colonic media for chitinolytic activity. The colon sac was lowered into the media and process was continued for up to $11 \mathrm{~h}$ as in vitro drug release study. After each phase, the organ segments were removed from the incubation medium. The contents of the sacs were filtered in a $0.22 \mathrm{~mm}$ pore membrane separately. The concentration of prednisolone in the medium was determined by HPLC. The tissues were homogenized using $5 \mathrm{ml}$ acetonitrile and the content was centrifuged at $3000 \mathrm{RPM}$ for $15 \mathrm{~min}$ the entire content was filtered using $0.45 \mu$ 
membrane filter and the obtained solution volume was made up to $10 \mathrm{ml}$ with acetonitrile. Samples were analysed by HPLC.

\section{Histopathological study}

The colon was fixed in $10 \%$ formalin in phosphate buffered saline for 1 week after which it was washed under running tap water for $2 \mathrm{~h}$. The samples were then dehydrated in graded ethanol and then embedded in paraffin wax. Sections were taken using a microtome. Sections were placed on a glass slide and paraffin was removed with xylene, stained with haematoxylin-eosin. Tissues were examined under microscope for ulceration, inflammation and goblet cell structure.

\section{MPO activity assay}

Tissue specimens accurately weighed in range $200-400 \mathrm{mg}$ were homogenized using $1 \mathrm{ml}$ hexadecyl trimethyl ammonium bromide buffer $(0.5 \%$ HTAB in $50 \mathrm{mM}$ phosphate buffer, $\mathrm{pH} \mathrm{6)}$ in ice cold conditions. After homogenization, the container was rinsed twice with $1 \mathrm{ml}$ of HTAB. The pooled $3 \mathrm{ml}$ homogenate of each specimen was sonicated and freezethawed three times to release the enzyme from the cells. The homogenate was centrifuged at $3,000 \mathrm{rpm}$ for $5 \mathrm{~min}$. $100 \mu \mathrm{l}$ of supernatant was combined with $2.9 \mathrm{ml}$ of $50 \mathrm{mM}$ phosphate buffer, $\mathrm{pH} 6$, containing $0.167 \mathrm{mg} / \mathrm{ml}$ of o-dianisidine dihydrochloride (ODA) and $0.0005 \% \mathrm{H}_{2} \mathrm{O}_{2}$ in an ice bath. The absorbance is measured at $460 \mathrm{~nm}$ (Merck Spectroquant Prove-600 UV-Visible spectrophotometer) against the blank (i.e., reagent without the supernatant). The MPO levels were determined from standard plot constructed using standard horse radish peroxidase. ${ }^{16}$

\section{Statistical analysis}

The data of ex vivo studies and MPO activity assay were reported as mean \pm standard deviation. Comparison among groups was done by performing unpaired t-test using Graphpad Prism software. Results having $\mathrm{p}$ value $<0.05$ were reported as significant.

\section{RESULTS}

Particle Size, Zeta Potential (ZP) and Percentage Entrapment Efficiency (\%EE)

The average size, $\mathrm{ZP}$ and \%EE data are given in Table 1 . The results were compared between plain liposomes, chitosan coated (CCLs) and eudragit encapsulated chitosan coated liposomes (ECLs). The average particle size of plain liposomes was found to be $99.90 \pm 0.2 \mathrm{~nm}$. After chitosan coating, the size increased to $235.8 \pm 0.1 \mathrm{~nm}$. Further increase in size of $290.5 \pm 0.2 \mathrm{~nm}$ was observed after encapsulating the coated liposomes

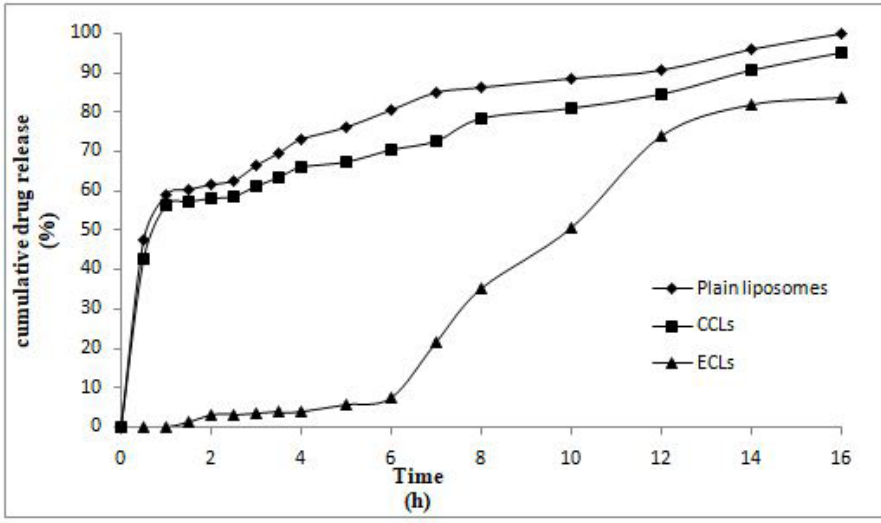

Figure 1: Cumulative drug release profiles of plain liposomes ( $\downarrow)$, Chitosan coated liposomes ( $\mathbf{\square})$ showing burst release within $1 \mathrm{~h}$ and Eudragit encapsulated chitosan coated liposomes $(\mathbf{\Delta})$ showing Tlag of 5-6 h [Source: Original Data]. within eudragit S-100 shell. Zeta potential of liposomes was $-33.1 \pm 0.3 \mathrm{mV}$ which increased to $+35.3 \pm 0.4 \mathrm{mV}$. After eudragit encapsulation, the charge reduced to $-32.5 \pm 0.2 \mathrm{mV}$. Entrapment efficiency of plain liposomes was $94.29 \pm 0.5 \%$ which reduced slightly after chitosan coating $(\% \mathrm{EE}=92.89 \pm 0.1 \%)$ and eudragit encapsulation $(\% \mathrm{EE}=90.43 \pm 0.5 \%)$.

\section{In vitro drug release profile}

Plain liposomes and CCLs showed burst release of $47 \%$ and $42 \%$ respectively within $1 \mathrm{~h}$ in gastric media. Appreciable lag time of 5-6 h was observed with the release of more than $20 \%$ and maximum release of $82 \%$ drug by $16^{\text {th }} \mathrm{h}$. The drug release profiles are shown in Figure 1.

\section{Ex vivo tissue-drug entrapment study}

The study was performed to evaluate the tendency of the drug to get entrapped within the inflamed tissue when incorporated in nanoformulations. The drug entrapped in inflamed colon tissue was found to be $22.58 \pm 2.52 \%$ which was highest when compared to healthy. The results are given in Table 2.

\section{Histopathological examination}

The efficiency of the formulation (ECLs) to deliver prednisolone to the inflamed colon in order to effectively treat the inflammation locally was evaluated by conducting histopathological examination after treatment. The formulation ECLs was successful in delivering the drug and localizing the therapy. The IBD induced rats treated with ECLs showed marked reduction in inflammation with evident remucosalization, reduction in focal ulceration and goblet cell distortion. The micrographs of the tissues are shown in Figure 2.

\section{MPO activity assay}

Estimation of MPO levels is a vital tool to estimate the extent of increase or reduction in inflammation of a tissue. The MPO levels of ECLs treated colon tissues were reduced significantly i.e. $900.25 \pm 1.31 \mathrm{ng} / \mathrm{ml}$ when compared to healthy and control groups. The data is reported in Table 3.

\section{DISCUSSION}

The negative charge, as well as desired particle size (around 99-100 nm) of uncoated liposomes, was due to the optimal cholesterol content that

Table 1: Particle size, zeta potential (ZP) and percentage entrapment efficiency (\%EE) of plain liposomes, CCLs and ECLs (mean \pm SD) [Source: Original Data].

\begin{tabular}{cccc}
\hline $\begin{array}{c}\text { Formulation } \\
\text { code }\end{array}$ & $\begin{array}{c}\text { Particle size } \\
(\mathrm{nm})\end{array}$ & $\begin{array}{c}\mathrm{ZP} \\
(\mathrm{mV})\end{array}$ & $\begin{array}{c}\mathrm{EE} \\
(\%)\end{array}$ \\
\hline Liposomes & $99.90 \pm 0.2$ & $-33.1 \pm 0.3$ & $94.29 \pm 0.5$ \\
CCLs & $235.8 \pm 0.1$ & $+35.3 \pm 0.4$ & $92.89 \pm 0.1$ \\
ECLs & $290.5 \pm 0.2$ & $-32.5 \pm 0.2$ & $90.43 \pm 0.5$ \\
\hline
\end{tabular}

CCLs - Chitosan coated liposomes; ECLs - Eudragit encapsulated chitosan coated liposomes; ZP - Zeta potential; EE - Entrapment efficiency; nm - nanometers; $\mathbf{m V}$ - milli volts.

Table 2: Percentage entrapment of drug in healthy and disease control (IBD) tissues (mean \pm SD) [Source: Original Data].

\begin{tabular}{ccccc} 
& \multicolumn{4}{c}{ Tissue-drug entrapment in various tissues } \\
Tissue & \multicolumn{4}{c}{ (\%) } \\
\cline { 2 - 5 } Group & Stomach & $\begin{array}{c}\text { Small } \\
\text { intestine }\end{array}$ & Colon & $\begin{array}{c}\text { External } \\
\text { media }\end{array}$ \\
\hline Healthy & 0 & $1.17 \pm 0.75$ & $9.42 \pm 2.68$ & $72.56 \pm 2.67$ \\
$\begin{array}{l}\text { Disease } \\
\text { control }\end{array}$ & 0 & $5.74 \pm 1.26$ & $22.58 \pm 2.52$ & $55.53 \pm 4.053$ \\
\hline
\end{tabular}




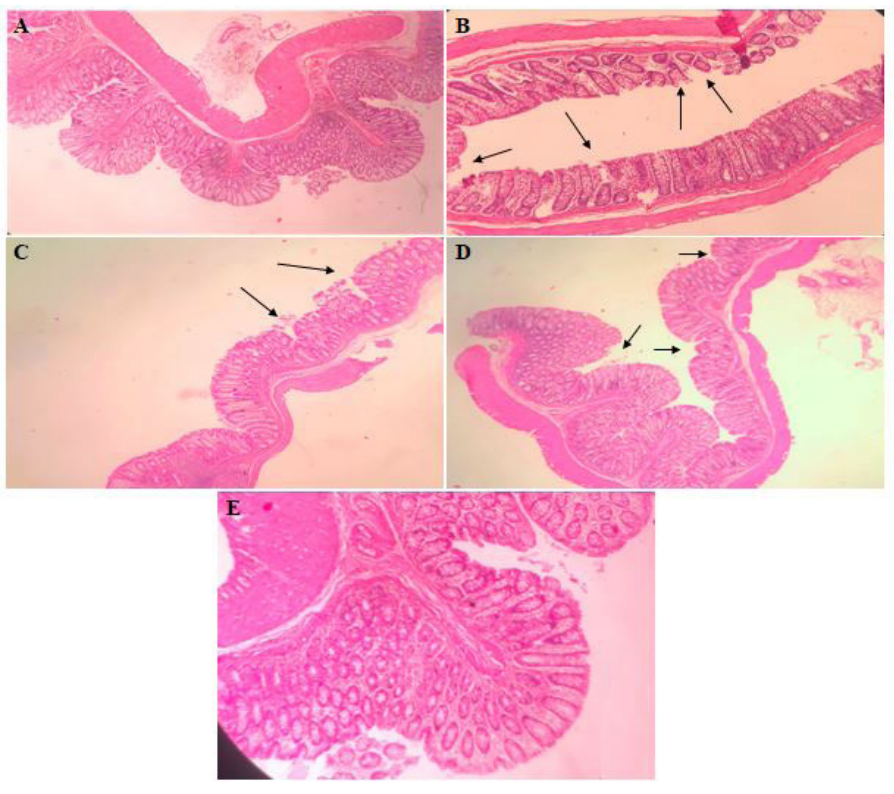

Figure 2: (a) Healthy rat colon with normal goblet cell structure and intact mucosa; (b)IBD induced colon with focal ulcerations, mucosal disruption and distorted goblet cell structure; (c)Placebo administered IBD induced colon with similar histopathological characteristics as the IBD induced group; (d) Standard drug treated colon showing slight signs of reduced ulcerations with slight goblet cell distortion; (e) ECLs treated colon with marked reduction in focal ulceration, intact goblet cell structure and evidence of re-mucosalization. [Source: Original Data]

Table 3: MPO levels in colon samples of different groups of rats (mean \pm SD) [Source: Original Data].

\begin{tabular}{cc}
\hline Groups & $\begin{array}{c}\text { MPO Levels } \\
(\mathrm{ng} / \mathrm{ml})\end{array}$ \\
\hline Healthy & $150.56 \pm 2.21$ \\
Disease control (IBD) & $2125.54 \pm 1.56$ \\
IBD+Placebo & $2130.46 \pm 1.38$ \\
IBD+Std drug & $1990.32 \pm 2.11$ \\
IBD+ECLs & $900.25 \pm 1.31$ \\
\hline
\end{tabular}

MPO - Myeloperoxidase; IBD - Inflammatory bowel disease; ng - Nanogram.

imparted the charge and prevented aggregation due to the presence of interparticular repulsive forces. Addition of chitosan coat increased the particle size as well as imparted a higher positive charge on the particle surface due to positively charged functional groups of chitosan. Eudragit encapsulation again increased the size but imparted a negative charge on the CCLs surface. Entrapment efficiency was higher due to the lipid solubility and incorporation of the drug in the lipid phase of the liposomes. Exposure of drug loaded liposomes to successive coating process slightly reduced the encapsulation efficiency due to the mechanical stress of the processes.

Drug release profiles of plain liposomes and CCLs showed burst release of the drug since uncoated liposomes are unable to withstand the acidic and enzymatic gastric environment and also chitosan being soluble in acidic medium fails to protect vesicles. In case of plain liposomes $47 \%$ of the drug released in $30 \mathrm{~min}$ and for CCLs it was $42 \%$. More than $70 \%$ of drug was released in the small intestine media before reaching the colonic region indicating the failure of both the systems for colon delivery of the drug. ECLs having eudragit concentration of $2 \% \mathrm{w} / \mathrm{v}$ for the stages where during $2 \mathrm{~h}$ in gastric conditions, $3 \mathrm{~h}$ in small intestine conditions showed only $4-5 \%$ drug release indicating that the liposomes are intact within the eudragit particles. Importantly, the formulation was resistant to degradation by sodium taurocholate. Eudragit shell solubilization occurred within $30 \mathrm{~min}$ of contact with colonic media which consequently led to drug release of more than $20 \%$. Exposure to the colon, corresponding to $12 \mathrm{~h}$ on the drug release curve led to approximately $73 \%$ drug release, showing that most the liposomes would have been exposed at this point of time and therefore chitosan degradation and subsequent drug release would follow. At the end of $16^{\text {th }} \mathrm{h}, 82 \%$ drug release was achieved. The formulation showed a satisfactory lag time $\left(\mathrm{T}_{\mathrm{lag}}\right)$ of 5-6 h which is required for colon targeted drug delivery systems. ${ }^{17}$

Nanoformulations have a tendency to adhere to inflamed colonic mucosa when compared to healthy tissue. To test this, everted sac method was used to evaluate the effect of ECLs on the entrapment of drug in both healthy and inflamed tissues as compared to pure drug. The percent drug entrapped for inflamed and healthy colon is $22.58 \pm 2.52$ and $9.42 \pm$ 2.68 respectively. The difference was statistically significant with p-value $<0.0001$ at $95 \%$ confidence interval. The concentration of drug remaining outside the tissue i.e. in the media was also determined which represents the unentrapped drug and it was found to be $55.53 \pm 4.053$ and $72.56 \pm 2.67$ for inflamed and healthy colon respectively. This shows that the entrapment of formulation is much more to inflamed colon as compared to healthy. ${ }^{18-20}$

Histopathological features in acute on chronic colitis are mucosal erosions, crypt shortening, oedema and infiltration of neutrophils in the mucosa and lamina propria. ${ }^{21}$ Compared to the normal group (Figure 2a), the IBD group exhibited marked erosion of the lamina propria, mucosa, focal ulcerations, distortion of goblet cells and inflammatory cell infiltration (Figure 2b). In standard drug-treated group (Figure 2d) and ECLs formulation-treated group (Figure 2e), mucosal erosion, distortion of goblet cells, ulceration and inflammatory cell infiltration tended to be less severe than those in the IBD group. Compared to the standard drug treated group, ECLs treated group showed faster healing and repair as there were very less ulcerations, mucosa showed signs of repair (re-mucosalization) and goblet cells distortion was also reduced, whereas in standard drug treated group, mucosa was not intact and prominent focal ulceration still persisted.

MPO is present in primary granules of neutrophils. In IBD, there is a larger infiltration of neutrophils in the inflamed tissue which leads to MPO release. ${ }^{22}$ This is evident from the data given in Table 3 that there is significant increase ( $p$-value $<0.0001)$ in MPO activity of disease control IBD group $(2125.54 \pm 1.56 \mathrm{ng} / \mathrm{ml})$ as compared to the healthy group $(150.56 \pm 2.21 \mathrm{ng} / \mathrm{ml})$. Decrease in the activity of MPO in tissue is the sign of tissue repair and healing. It can be seen from the histogram a significant reduction in MPO level $(p$-value $<0.0001)$ when treated with formulation ECLs $(900.25 \pm 1.31 \mathrm{ng} / \mathrm{ml})$ as that with standard prednisolone given orally $(1990.32 \pm 2.11 \mathrm{ng} / \mathrm{ml})$ and in contrast to IBD group..$^{23}$ The difference between the MPO levels of standard drug treated group and IBD control group was not statistically significant with $p$-value equal to 0.0651 ( $p>0.05)$. The colon targeted formulation ECLs inhibited MPO activity suggesting that infiltration of neutrophils thus proving its efficiency.

\section{CONCLUSION}

Liposomes have been reported to show selective accumulation at the inflamed sites. The studies conducted showed that the eudragit encapsulated chitosan coated liposome formulations (ECLs) having desired characteristics were successfully formulated by lipid film hydration method. Entrapment efficiency data showed successful incorporation of prednisolone within the liposomes. The dual polymer coating 
protected the drug from releasing in the upper GIT by exhibiting an in vitro lag time of 5-6 h. Ex vivo studies showed that nanoformulations have a higher affinity towards inflamed tissues which further aids the efficiency of the formulation. The efficiency of the coated liposomes in vivo was confirmed by the results of histopathological studies and MPO activity assay of the colon tissue sections. Thus it can be concluded that such type of liposomal carrier system can be utilized to target the inflamed colonic tissue specifically.

However, there is a need to further establish the efficicacy of these formulations in human subjects.

\section{ACKNOWLEDGEMENT}

The authors would like to thank NGSM Institute of Pharmaceutical Sciences for providing the facilities to conduct the experiments.

\section{CONFLICT OF INTEREST}

The authors declare no conflict of interest.

\section{ABBREVIATIONS}

CCLs: Chitosan coated liposomes; ECLs: Eudragit encapsulated chitosan coated liposomes; ZP: Zeta potential; EE: Entrapment efficiency; nm: nanometers; mV: milli volts; MPO: Myeloperoxidase; IBD: Inflammatory bowel disease; ng: Nanogram.

\section{REFERENCES}

1. Ravi $V$, Pramod KTMS. Novel colon targeted drug delivery system using natural polymers. Indian J Pharm Sci. 2008;70(1):111-3.

2. Garala RJ, Shirolkar SV, Deshpande AD, Kulkarni AD. Colon targeted drug delivery system of prednisolone by press coating technique: effect of different grades of hydroxyethylcellulose in coat. Res J Pharm Tech. 2011;4(3):405-10.

3. Chauhan CS, Naruka PS, Rathore RS, Badadwal V. Formulation and evaluation of Prednisolone tablet for colon targeted drug delivery system. J Chem Pharm Res. 2010;2(4):993-8.

4. Patel DB, Patel JK. Liposomal drug delivery of metronidazole for local treatment of vaginitis. Int J Pharm Sci Nanotech. 2009;2(9):421-8.

5. Essa EA. Effect of formulation and processing variables on the particle size of sorbitan monopalmitate niosomes. Asian J Pharm. 2010;4(4):227-36.

6. Rajashree H, Sneha G. Preparation, optimization and evaluation of diallyl disulphide loaded liposomes. Der Pharma Chemica. 2017;9(7):46-53.

7. Goncalves MC, Mertins O, Pohlmann AR, Slveira NP, Guterres SS. Chitosan coated liposomes as an innovative nanocarrier for drugs. J Biomed Nanotechnol. 2012;8(2):240-50.

8. De Leo V, Milano F, Mancini E, Comparelli R, Giotta L, Nacci A, et al. Encapsulation of curcumin loaded liposomes for colonic drug delivery in a $\mathrm{pH}$ responsive polymer cluster using a $\mathrm{pH}$ driven and organic solvent free process. Molecules. 2018:23(739):1-15.

9. Rajendran V, Rohra S, Raza M, Hasan GM, Dutt S, Ghosh PC. Stearylamine liposomal delivery of monensin in combination with free artemisinin eliminates blood stages of Plasmodium falciparum in culture and P. berghei infection in murine malaria. Antimicrob Agents Chemother. 2016;60(3):1304-18.

10. Cetin M, Atila A, Kadioglu Y. Formulation and In vitro characterization of eudragit L100 and eudragit L100-PLGA nanoparticles containing diclofenac sodium. AAPS Pharm Sci Tech. 2010;11(3):1250-57.

11. Nayak S, Patel H, Kesarla R, Rayasa RM. Colon delivery of 5-Fluorouracil using cross-linked chitosan microspheres coated with eudragit S 100. Int J Drug Del. $2011 ; 3(2): 260-8$

12. Bastaki SMA, Ahmed MMA, Zaabi AA, Naheed Amir N, Adeghate E. Effect of turmeric on colon histology, body weight, ulcer, IL-23, MPO and glutathione in acetic-acid-induced inflammatory bowel disease in rats. BMC Complem Alter Med. 2016;16(72):1-14.

13. Younessi P, Avadi MR, Shamimi K, Sadeghi AMM, Moezi L, Nahid E, et al. Preparation and ex vivo evaluation of TEC as an absorption enhancer for poorly absorbable compounds in colon specific drug delivery. Acta Pharm. 2004;54(4):339-45.

14. Avadi MR, Sadeghi AMM, Dounighi NM, Dinarvand R, Atyabi F, Rafiee-Tehrani M. Ex vivo evaluation of insulin nanoparticles using chitosan and arabic gum. ISRN Pharm. 2011;1-7.

15. KShirsagar SJ, Bhalekar MR, Shukla GN, Mohapatra SK. Development and evaluation of multiparticulate colon targeted drug delivery system by combine approach of pH and bacteria. Int J PharmTech Res. 2011,3(2):1139-49.

16. Kondamudi PK, Kovelamudi H, Mathew G, Nayak PG, Rao MC, Shenoy RR Investigation of sesamol on myeloperoxidase and colon morphology in acetic acid-induced inflammatory bowel disorder in albino rats. The Scientific World J. 2014;1-7.

17. Patel MM, Amin AF. Formulation and development of release modulated colon targeted system of meloxicam for potential application in the prophylaxis of colorectal cancer. Drug Del. 2011;18(4):281-93.

18. Leonard F, Ali H, Collnot EM, Crielaard BJ, Lammers T, Storm G, et al. Screening of budesonide nanoformulations for treatment of inflammatory bowel disease in an inflamed 3D cell-culture model. ALTEX. 2012;29(3):275-85.

19. Cocoa R, Plapieda L, Pourcelle V, Jérômec C, Braydend DJ, Schneider Y, et al. Drug delivery to inflamed colon by nanoparticles: Comparison of different strategies. Int J Phar, .2013;440(1):3-12.

20. Chen $\mathrm{Q}$, Xiao B, Merlin D. Nanotherapeutics for the treatment of inflammatory bowel disease. Exp Rev Gastroenterol Hepatol. 2017;11(6):495-7.

21. Machtaler S, Knieling F, Luong R, Tian L, Willmann JK. Assessment of inflammation in an acute on chronic model of inflammatory bowel disease with ultrasound molecular imaging. Theranostics. 2015;5(11):1175-86.

22. Masoodi I, Tijjani BM, Wani $H$, Hassan NS, Khan AB, Hussain S. Biomarkers in the management of ulcerative colitis: a brief review. German Medi Sci. 2011;9:1-7.

23. Tang $\mathrm{H}$, Xiang $\mathrm{D}$, Wang $\mathrm{F}$, Mao J, Tan X, Wang Y. 5-ASA-loaded $\mathrm{SiO}_{2}$ nanoparticles-a novel drug delivery system targeting therapy on ulcerative colitis in mice. Mol Med Rep. 2017;15(3):1117-22.

Article History: Submission Date : 30-08-2018; Revised Date : 04-10-2018; Acceptance Date : 15-11-2018.

Cite this article: Ben MS, Marina K, Mukund GS. Eudragit S-100 Encapsulated Chitosan Coated Liposomes Containing Prednisolone for Colon Targeting: In vitro, Ex vivo and In vivo Evaluation. J Young Pharm. 2019;11(1):7-11. 